\title{
Optimization Analysis of Comprehensive Budget Management System- _-An Example of Hualing Electric Power Company
}

\author{
Linli Bian \\ School of Management, Yulin University, China,719000 \\ 80335993@qq.com
}

Keywords: Comprehensive budget management; Budget management system; Hualing electric power company

\begin{abstract}
Under the guidan-ce of the basic theoretical framework of comprehensive budget management, this paper analyzes and reviews the current situation of comprehensive budget management system of Hualing electric power company. This paper points out the existing problems, and puts forward the comprehensive budget management organization system, the comprehensive budget management system, and the construction information platform. A series of optimization measures for training management talents and perfecting the overall budget evaluation mechanism. This research will give Hualing electric power companies and other power enterprises to complete the overall budget management system.
\end{abstract}

\section{Introduction}

Hualing electric power company was founded in 1990, mainly engaged in power development, maintenance, operation sales and other aspects of the business. In order to achieve the goal of the company's development, we need to adopt the modern management mode. With comprehensive budget management, we can plan and arrange the production and financial achievements of the company in the future. This is helpful to the realization of the strategic goal of the company. Although the company's budget management has been running for a long time, it has initially set up a budget management framework, but the effectiveness of budget management failed to play effectively, and it is difficult to adapt to the rapid development of the company and need to improve and improve. Therefore, optimizing the overall budget management system, strengthening the operation and effectiveness of the system has become an important task for the Hualing electric power company. But budget management is not an isolated management system, and in enterprise management is in the core position in the process of improvement and perfection, both need accurate positioning and careful thinking. Need other management system to support and support.

\section{Existing problems of Hualing electric power company' comprehensive budget management}

The budget organization system needs to be improved. Hualing electric power company in the budget organization system is not clear, the responsibility is unclear, the scope is too narrow, which directly restricts the implementation effect of comprehensive budget management. First, Organizational functions are not distributed. Hualing electric power company's budget daily management work is responsible for the budget management office, but because there is no powerful system constraint, is often the finance department's leading budget management process. Lack of cooperation and cooperation with other departments. As a functional department, the finance department shall carry out the coordination of all departments within the company, and deal with the interests of all parties, and it is difficult to cause contradictions. Second, The budget supervision agency is not set up independently. The budget supervision work of Hualing electric power company is in charge of the budget management office, and there is no clear regulation on the supervision of content and supervision. On the one hand, contrary to the principle of the separation of management and supervision, on the other hand, the overall budget management 
system has lost credibility, and the internal control has left a hidden danger. Third, The subordinate unit has not set up a specialized budget management institution. The lower unit of Hualing electric power company is only a budget executive, and after the budget is issued, there is no professional organization to analyze and monitor it, and lack of a professional platform to upload.

The budget system is not sound. Budget preparation method. The formulation of the budget is not reasonable. Different budget methods have different characteristics, suitable for different enterprises, but also suitable for different budget content. There should be a variety of methods to use the budget, but the Hualing power company uses a fixed budget and an incremental budget for the selection of methods, and the budget is too simple. This will lead to a big discount on the overall budget implementation of the company. The contents of the budget. The content of the budget is missing, and there is no specialized fund-raising budget, just according to the business budget and the capital budget, and the total amount of capital flows out of the year. The scale of the gap and the financing cost, as the financial budget is expected to be the balance sheet, is expected to be the basis of the cash flow statement, and financing channels, financing time, and so on. There is no corresponding implementation plan. Budget preparation procedures. On the design of the budget, both the and the of the, which is too complex or too simple, are not conducive to the coordination of the budget and the review. It is possible to create contradictions, cause contradictions, and possibly obscure targets, resulting in a waste of resources.

Budget management information system cannot meet the needs of budget control. At present, Hualing electric power company has established a budget management information system, and through the budget management information system, real-time monitoring budget implementation, into the control of the operation. But the system is not yet sound, and there is no information sharing between the financial management system and other management information systems such as the business system. The budget control is basically achieved by manual control, which not only affects the efficiency of the work, but also affects the accuracy of the budget and the timeliness of the analysis. This will enable the Hualing electric power company to do not achieve the accurate, timely delivery and summary, can not achieve the synchronous control of business activities and budget, dynamic reflection of the whole process management. As well as the real-time comparative analysis $\mathrm{g}$ in the system, it is very difficult for budget management, and this information is often the basis of management decision and management.

The budget lacks effective appraisal mechanism. First, the budget appraisal is not strict enough to make the evaluation link form. The evaluation and rewards and penalties are not strict, and have become one of the important reasons that affect the overall budget management of Hualing electric power company. In the process of carrying out comprehensive budget management in the company, we shall be responsible for the performance of the executive department of the budget standards, and by the results of the examination and punishment. The evaluation personnel will often be involved in the evaluation of personal feelings, the evaluation of the evaluation, the loss of justice and fairness; And the evaluation party often deliberately avoid subjective factors, emphasizing the impact of objective factors on the performance of their work, and the form of evaluation work. The budget assessment is not strict, and the budget has not become the standard of examination. Second, the lack of the corresponding incentive mechanism, the budget goal is difficult to achieve. Hualing electric power company's budget management lacks incentive mechanism, can not mobilize the enthusiasm of the staff, so that the staff can not complete the budget target. Budget management should be a clear, responsible, strict management system, which can guarantee the consistency of organizational goals and effectively stimulate the initiative of the organization. The main body of budget management is the majority of employees, so employees are the decisive factor in budget management. If budget management cannot effectively motivate and guide employees to work for budget goals, the goal of budget management is hard to achieve. 


\section{Optimization measures of Hualing electric power company' comprehensive budget management}

Perfect comprehensive budget management organization system. First is rational distribution of organizational functions. When the Hualing electric power company is setting up the organization function, it is necessary to divide the budget responsibility center rationally and ensure the equality of responsibility, rights and obligations. At the same time, we should strengthen the cooperation and cooperation between various functional departments, and form a clear, responsible, clear, cooperative, efficient working mechanism and responsibility mechanism. Provide effective organizational security for comprehensive budget management. Second is setting up an independent budget supervision agency. Hualing electric power companies should set up independent supervision institutions within the company, and the specific work is: (1) to supervise the implementation of various processes in the process of budget management, to ensure that the examination and approval procedures are complete, without authority. To conceal such irregularities; (2) to supervise the results of the evaluation of the budget and ensure that the examination data, process and procedures are in conformity with the requirements of the company's system; (3) to supervise the daily work of the budget management committee and budget management office; (4) the office will submit the annual budget supervision report to the general manager. Third is setting up a budget management organization at a lower level. The Hualing electric power company shall set up a budget management institution at the lower level, undertake the budget management of the higher level and deploy the budget management work of the corresponding units and subordinate units.

Improve the overall budget management system. One is budget preparation method. Hualing electric power company should be on the original budget method, increase other budget methods, such as elastic budget, zero-base budget, rolling budget, and so on. In the choice, according to the characteristics of the budget project or object characteristics, flexible use of the corresponding methods, and should also consider the operating environment, market environment, production management, budget projects, and. Management level, the compilation of personnel of the six factors. In this way, we can improve the accuracy of the budget and give full play to the guidance of the budget. The other one is the contents of the budget. Hualing electric power company should take 2 measures to optimize the content of budget; 1 is to further refine the existing content, such as the specialized decision-making budget, not only to determine the amount of investment, but also to the specific payment point, clear the progress of each time; 2 is to supplement the fund-raising budget, to do the overall plan, to guard against the risk of funds to ensure efficiency and cost reduction. And the last one is budget preparation procedures. Hualing electric power company in the optimization of budgeting procedures to deal with different business and try to unify the requirements, to eliminate specialization, to follow the basic principles of fairness and transparency, design a set of practical,. The simple process, the maximum integration between the lower and lower levels, the long-term goal of the proposal, fully play the role of comprehensive budget management.

Establish information platform and train management talents. Firstly, establishing information platform. In the process of building information system, information is carried out through the whole process of enterprise production and operation, and all-round control and supervision. At the same time, the integration of data, through the enterprise logistics, information flow, capital flow, internal control management and audit flow and other information, to achieve the six-flow integration, enhance the efficiency of enterprises. Provide scientific data based on the preparation, supervision and evaluation of the comprehensive budget. Information can make the enterprise more scientific and accurate according to the past management situation to make a new plan, and according to the information system in time to reflect the implementation of the budget. To make a quick and reasonable adjustment, to ensure the flexibility of the budget. Secondly, Training management talents. In order to change the environment of enterprise management, improve the efficiency of enterprise management, realize the comprehensive budget management system, the enterprise should cultivate the management talents, and the management accounting talents are indispensable. The professional management accounting talent is the necessary condition 
for the enterprise to implement comprehensive budget management. Enterprises can provide high-end management talents for enterprises by recruiting high-level talents, internal key training, and so on. Management talents can correctly grasp the situation and develop opportunities, science should be on the situation of crisis, for the future development of enterprises to escort.

Improve the overall budget evaluation mechanism. Establish the appraisal and supervision mechanism to ensure the justice of the appraisal. Establish a sound budget appraisal, reward and punishment system and budget internal audit system. In order to ensure the seriousness of the budget, we must strictly control the implementation of the budget and assess the performance of the budget. To set up independent internal audit institutions within the company, supervise the process and result of budget evaluation, reduce people to interfere with factors, ensure the fairness, fairness and seriousness of the results of evaluation. Realize self-restraint. Improve the budget incentive mechanism and improve the enthusiasm of all personnel. The incentive system should embody the principle of fairness, and in the process of evaluating the evaluation system, we should fully reflect the principle of fairness, and do so much, so as to encourage advanced and backward role. We can't engage in equalitarianism, which will cause great harm. The incentive mechanism should be combined with the appraisal system, and adopt different incentive mechanism according to the characteristics of this enterprise. At the same time, we should not only adopt one kind of incentive method, but should consider the individual differences of the age, education, personality, gender, and so on. Enable the staff to really be able to work in the most suitable position. To improve the budget incentive mechanism, to achieve the results of the evaluation and management staff of the annual salary and the total salary of employees. Moreover, it is also necessary for each employee to understand the relationship between the budget performance and the rewards and punishments before the budget is carried out, and the goal of the individual will be combined with the overall goal of the budget. Make the employees self-discipline, improve their work efficiency, and promote the completion of budget indicators.

\section{References}

[1] Hou Longwen, Hou Yan, He Ying: Modern Comprehensive Budget Management (Economic Management Press, China 2012), p.32-35.

[2] Huang Hongqiang. Discussion on Optimization of Comprehensive Budget Management System of Electric Power Company, Financial Supervision, Vol. 7 (2016) No.13, p.88-90.

[3] Xue Yuxing. Research on Overall Budget Management of B Company (MS., Shenyang University of Technology, China 2016), p.14-17.

[4] Zhang Lu. Research on Comprehensive Budget Management of Electric Power Company in Shanxi Province (MS., Wuhan Textile University, China 2015), p.11-14.

[5] Wang Lan. Brief Analysis on the Necessity of Comprehensive Budget Management for Enterprises, China Journal of Commerce,Vol. 16 (2015) No.33, p.59-61. 